\title{
COMPETIÇÃO ENTRE ENXERTIAS DE MESA E DE CANTEIRO EM NOGUEIRA PECA *
}

VLADIMIR RODRIGUES SAMPAIO $* *$ DECIO BARBIN $* * *$

\section{RESUMO}

Realizou-se um experimento de propagação de nogueira pecã no qual se fez a competição da enxertia de mesa com a enxer tia no porta-enxerto implantado no próprio canteiro. As operaçôes foram realizadas em seedlings do cultivar moneymaker com um ano de idade. Foram experimentados três tratamentos: 1) enxertia no próprio local; 2) enxertia de mesa e plantio no canteiro no mesmo dia; e 3) enxertia de mesa, calejamento controlado e plantio no canteiro, resultando em 64,70 e $90 \%$ de sobrevivência das mudas, respectivamente. As mudas, mensuradas após um ano da enxertia, mostraram fraco desenvolvimento vegetativo, apresentan-

\footnotetext{
* Entregue para publicação em 05/09/1980.

** Departamento de Agricultura e Horticultura, E.S.A. "Luiz de Queiroz", USP.

*** Departamento de Matemática e Estatística, E.S.A. "Luiz de Queiroz", USP.
} 
do os tamanhos de 39,$7 ; 21,4$ e $21,5 \mathrm{~cm}$ para os tratamentos 1,2 e 3 , respectiva mente, tamanhos estes medidos a partir dā região enxertada.

\section{INTRODUÇÃO}

A enxertia da nogueira pecã pode ser realizada através da garfagem no inverno, ou da borbulhia, no verão, sobre seeđlings da mesma espécie (BAILEY \& WOODROOF, 1932; BLONDEL, 1951; CHANDLER, 1951; BITTENCOURT, 1952; SIMÃO, 1971), sendo necessários três anos, a partir da semente, para se obter a muda vigorosa de raízes nuas.

Através de trabalho realizado por SAMPAIO \& BARBIN (no prelo), constatou-se a possibilidade da propagação da nogue ra pecã, pelo método da enxertia de mesa, utilizando como por ta-enxertos raỉzes de seedlings com um ano de idade, com pos terior desenvolvimento das plantas no campo do viveiro. Embo ra fôsse viável a enxertia, verificou-se que as plantas apré sentavam fraco desenvolvimento vegetativo em seu primeiro ano após a operação, sendo necessários dois anos para a muda atingir tamanho comercial.

0 presente experimento foi realizado, visando-se competir a enxertia de mesa com a enxertia no próprio local da formação do seedling, no canteiro, procurando observar-se a sobrevivência das plantas enxertadas e também seu desenvolvi mento vegetativo.

\section{MATERIAL E MÉTODOS}

Os porta-enxertos foram obtidos por semeadura em alfobres de alvenaria, com $40 \mathrm{~cm}$ de profundidade, preenchidos com solo classificado como Terra Roxa Estruturada, série Luiz de Queiroz, segundo RANZANI et alii (1966), misturado com es têrco de curral, cerca de 40 litros por metro quadrado de cañ teiro.

Um ano após a semeadura, a 31 de julho de 1975, foram executadas as enxertias, por garfagem de fenda ou inglês-com 
plicado, feitas em laboratório (enxertia de mesa) e no próprio canteiro. Na enxertia de mesa, o porta-enxerto era um segmento de raỉz com $20 \mathrm{~cm}$ de comprimento, tomado da região de maior diâmetro, do seedling arrancado do viveiro. As enxertias em todos os tratamentos foram realizadas a cerca de $3 \mathrm{~cm}$ da região do coleto dos seedlings. A seguir as partes foram amarradas com barbante e a região ferida recoberta com fitilho plástico. No tratamento onde se fêz calejamento pré plantio, as plantas permaneceram por 28 dias à temperatura de $26^{\circ} \mathrm{C}$, dentro de sacos plásticos, envoltas em Sphagnum umidecido.

0 desenvolvimento das plantas ocorreu no próprio canteiro, recebendo 3 adubações com sulfato de amónio; a primei ra a $16 / 10 / 75$, com o adubo dissolvido em água, 3 gramas por litro. As demais foram por cobertura, colocando-se 10 gramas do adubo por planta, nas datas de 04/12/75 e 28/01/76.

0 experimento foi delineado em blocos ao acaso, com 3 tratamentos e 10 repetições. Cada parcela com 5 plantas, espaçadas de $25 \times 25 \mathrm{~cm}$. Os tratamentos foram os seguintes:

Tratamento 1: enxertia executada no porta-enxerto implantado no canteiro;

Tratamento 2: enxertia de mesa e plantio no canteiro no mesmo dia;

Tratamento 3: enxertia de mesa e plantio no canteiro após 28 dias de permanência em ambiente úmido a $26{ }^{\circ} \mathrm{C}$.

0 experimento foi encerrado a 05/08/76. Verificou-se na ocasião o número de plantas sobreviventes. As mudas foram arrancadas e mensuradas; as brotações do enxerto a partir da região enxertada e os diâmetros do porta-enxerto enxerto a $5 \mathrm{~cm}$ daquela mesma região.

\section{RESULTADOS E DISCUSSÃO}

Os resultados estão na Tabela 1 . 
Tabela 1 - Médias do número de mudas de nogueira pecã produzidas, do desenvolvimento dos enxertos e dos diâmetros dos enxertos e porta-enxertos mensurados a $5 \mathrm{~cm}$ da região enxertada

\begin{tabular}{cccccc}
$\begin{array}{c}\text { TRATA- } \\
\text { MENTOS }\end{array}$ & $\begin{array}{c}\text { Númerode mudas } \\
\text { Transf. } \sqrt{\mathrm{x}+0,5}\end{array}$ & $\%$ & $\begin{array}{c}\text { Brotação } \\
\text { do enxerto }\end{array}$ & $\begin{array}{c}\text { Diâmetro } \\
\text { do enxerto }\end{array}$ & $\begin{array}{c}\text { Diâmetrodo } \\
\text { porta- } \\
\text { enxerto }\end{array}$ \\
\hline 1 & $1.895 \mathrm{~b}$ & 64 & $39.7 \mathrm{~cm} \mathrm{a}$ & $1.200 \mathrm{~cm} \mathrm{a}$ & $2.037 \mathrm{~cm} \mathrm{a}$ \\
2 & $1.988 \mathrm{ab}$ & 70 & $21.4 \mathrm{~cm} \mathrm{~b}$ & $0.909 \mathrm{~cm} \mathrm{~b}$ & $1.517 \mathrm{~cm} \mathrm{~b}$ \\
3 & $2.227 \mathrm{a}$ & 90 & $21.5 \mathrm{cmb}$ & $0.947 \mathrm{~cm} \mathrm{~b}$ & $1.445 \mathrm{~cm} \mathrm{~b}$ \\
\hline
\end{tabular}

C.V. $=13.65 \%$ e D.m.s. a $5 \%$ para número de mudas $=0.297$ C.V. $=42.27 \%$ e D.m.s. a $1 \%$ para brotação do enxerto $=11.39$

C.v. $=18.80 \%$ e D.m.s. a $1 \%$ para diâmetro do enxerto $=0.181$ C.V. $=21.60 \%$ e D.m.s. a $1 \%$ para diâmetro do porta-enxerto $=0.368$

0 número de mudas sobreviventes foi muito bom, o melhor resultado acontencendo para o tratamento 3 , enxertia de mesa com calejamento controlado, com sobrevivência de $90 \%$ dos enxertos realizados. Este resultado diferiu estatisticamente daquele obtido pelo tratamento 1 , enxertia no próprio cantei ro, o qual acusou a produção de $64 \%$ de mudas. 0 tratamentó 2 , enxertia de mesa e plantio no canteriro no mesmo dia. resultou em $70 \%$ de sobrevivência, não diferindo estatisticamen te dos demais tratamentos.

Quanto ao desenvolvimento das plantas, constatou-se que - enxerto no próprio canteiro propiciou maior crescimento das plantas, pois, este tratamento diferiu dos dois outros para os três parâmetros mensurados. Através da observação do parâ metro brotação do enxerto, o qual foi medido a partir da região do enxerto, verifica-se que mesmo para o tratamento 1 , o melhor resultado, que o enxerto de pecã, tem fraco desenvolvimento de sua parte aérea, quando a enxertia é feita em seedlings com um ano de idade. 


\section{CONCLUSÕES}

1 - A enxertia de mesa com calejamento controlado mostrou-se excelente método para obtenção de mudas de nogueira pecã, com desenvolvimento em canteiro;

2 - A enxertia de mesa com calejamento controlado, mostrouse superior à enxertia realizada no próprio canteiro, on de estavam e permaneceram os seedlings;

3 - Os enxertos de nogueira pecã em seedlings com um ano de idade, mostraram fraco desenvolvimento da parte aérea no primeiro ano após a enxertia.

4 - A enxertia de mesa em nogueira pecã retardou o desenvolvimento da parte aérea àa muda, em comparação à enxertia no próprio local.

\section{STMMARY}

A COMPARISON BETHEEN BENCH AND FIELD GRAFTING

IN PECANS.

A trial was carried on pecan propagation, comparing bench grafting and grafting of rootstocks in the seed-beds.

One year old seecings of cultivar moneymaker were used as rootstocks.

Treatments were as follows: 1) grafting in the seedbed; 2) bench grafting and replanting on the same day; and, 3) bench grafting with controlied growing calious.

One year later, results were 64,70 and $90 \%$ survival, respectively. Plants showed poor growth, being $39.1,21.4$ and $21.5 \mathrm{~cm}$ high.

\section{IITERATURA CITADA}

BAILEY, J.E.; WOODROOF, J.G., 1932. Propagation of pecans. Georgia Exp. Sta. Bu11. 172, 22p. 
BITTENCOURT, P.V.C., 1952. Instruções para a cultura da nogueira pecã, Inst. Agr. de Campinas, Bol. 27, 6p.

BLONDEL, L., 1951. Le meillense method de greffafe da pecanier. Fruits et Prim. 21: 273-274.

CHANDLER, W.H., 1957. Decidous orchards, Lea \& Febiger, 3a. ed., Filadelphia, 436 p.

RANZANI, G.; FREIRE, 0.; KINJO, T. Carta do solo do município de Piracicaba, E.S.A. "Luiz de Queiroz", 85p.

SAMPAIO, V.R.; BARBIB, D., 1980. Enxertia de mesa de nogueipecã em raỉzes de seedlings. An. Esc. Sup. Agric. "Luiz de Queiroz" 37: 